\title{
KORELASI ANTARA KELIMPAHAN VEGETASI MANGROVE DAN KERANG TOTOK Polymesoda erosa DENGAN FAKTOR LINGKUNGAN DI SEGARA ANAKAN, CILACAP
}

\author{
Mia Azizah \\ Program Studi Biologi FMIPA Universitas Nusa Bangsa Bogor \\ Jl. KH Soleh Iskandar KM 4 Cimanggu Tanah Sareal, Bogor 16166 \\ *e-mail : mia.azizah90@yahoo.com
}

\author{
ABSTRACT \\ Correlation Between Abundance of Mangrove Vegetation and Totok Clam \\ (Polymesoda erosa) to Environmental Factors in Segara Anakan, Cilacap
}

\begin{abstract}
Segara Anakan ecosystem is one of the largest estuary in Java which has a high biodiversity. One of the biota totok clam (Polymesoda erosa) that live in mangrove forests. These clams have high economic value. The study aimed to determine the correlation of abundance between mangrove community and totok clam (P. erosa), because of abiotic environmental factors in Segara Anakan, Cilacap. Research using survey methods and sampling techniques. Sampling point were 11 stations and were 3 plot sampling respectively. The data analyzed using correlation analysis of BIO - ENV. The correlation value of the environmental factors and mangrove community was 0.362 , and the correlation value of the environmental factor and the abundance of $P$. erosa was 0.412. The correlation value of mangrove vegetation with an abundance Polymesoda erosa had a value of 0.468 .
\end{abstract}

Keywords: correlation, mangroves, Polymesoda erosa, Segara Anakan

\begin{abstract}
ABSTRAK
Ekosistem Segara Anakan merupakan salah satu estuaria terbesar di Pulau Jawa yang memiliki keanekaragaman hayati yang tinggi. Salah satu biota yang ada adalah kerang totok(Polymesoda erosa) yang hidup berasosiasi dalam hutan mangrove. Kerang ini memiliki nilai ekonomis yang cukup tinggi. Penelitian ini bertujuan untuk mengetahui korelasi antara kelimpahan komunitas mangrove dan kelimpahan kerang totok (P. erosa), yang disebabkan faktor lingkungan abiotik P. erosa di Segara anakan, Cilacap. Penelitian menggunakan metode survei dan teknik pengambilan sampel. Titik sampling dibuat 11 stasiun dengan tiap stasiun diambil 3 plot. Data dianalisis dengan menggunakan analisis korelasi BIO-ENV. Nilai korelasi faktor lingkungan dengan struktur komunitas mangrove sebesar 0,362, dan nilai korelasi faktor lingkungan dengan kelimpahan $P$. erosa sebesar 0,412. Nilai korelasi vegetasi mangrove dan kelimpahan kerang totok memiliki nilai sebesar 0,468 .
\end{abstract}

Kata kunci: korelasi, mangrove, Polymesoda erosa, Segara Anakan

\section{PENDAHULUAN}

Hutan mangrove merupakan tipe vegetasi yang khas, terdapat di daerah pantai tropis dan subtropis. Vegetasi mangrove umumnya tumbuh subur di daerah pantai yang landai di dekat muara sungai dan pantai yang terlindung dari hempasan gelombang. Karakteristik habitat yang menonjol di hutan mangrove adalah jenis tanah lumpur; lempung atau pasir; serta menerima pasokan air tawar yang cukup dari darat seperti dari sungai; mata air; dan air tanah; serta air payau dengan salinitas 2-22 ppt (Irwani et al.,2006). Kondisi faktor lingkungan tersebut menyebabkan habitat mangrove bersifat spesifik yang hanya dapat ditempati oleh jenis tumbuhan dan fauna tertentu yang telah teradaptasi dengan lingkungan setempat (Hogarth, 2007).

Segara Anakan adalah salah satu kawasan hutan mangrove yang terletak pada koordinat $108^{\circ} 46^{\prime}-109^{\circ} 03^{\prime} \mathrm{BT}$ dan $07^{\circ} 34^{\prime}-07^{\circ} 47^{\prime}$ LS di bagian 
selatan pulau Jawa tepatnya di Kabupaten Cilacap, Jawa Tengah. Luas kawasan Segara Anakan sekitar 34.018 ha. Lagunanya tidak berhubungan langsung dengan ombak Samudera Hindia karena dibatasi oleh Pulau Nusakambangan. Sejak tahun 1978, luasan ekosistem mangrove mengalami fluktuasi sebagai akibat dari deforestasi dan perluasan mangrove di area sedimentasi yang baru atau tanah timbul. Dari tahun 1978 sampai 1987 sekitar 3003,6 ha mangrove hilang, akan tetapi seluas 1741,1 ha mangrove baru terbentuk di area tanah timbul (Ardli dan Wolff, 2008).

Segara Anakan merupakan salah satu estuaria terbesar di Pulau Jawa yang tinggi keanekaragaman hayatinya. Diantara biota yang terdapat adalah kerang totok ( $P$. erosa) yang berasosiasi dengan hutan mangrove. P. erosa termasuk dalam family Corbiculidae yang hidup di ekosistem mangrove dan banyak dijumpai di kawasan IndoPasifik Barat yaitu mulai dari India, Malaysia, Indonesia, Thailand, Vietnam, Burma, Philipina. Kerang ini memiliki nilai ekonomis yang cukup tinggi sehingga banyak dimanfaatkan oleh masyarakat. Namun, informasi mengenai sifat-sifat ekologisnya belum banyak diketahui (Irwani et al., 2006).

Menurut Kusmana (2002) kerang totok (Polymesoda erosa) disebut juga dengan Geloina erosa. Secara morfologi Polymesoda erosa mempunyai bentuk cangkang seperti piring atau cawan yang terdiri dari dua katub yang bilateral simetris, pipih pada bagian pinggirnya dan cembung pada bagian tengah cangkang, bentuk cangkang yang equivalve atau berbentuk segitiga yang membulat, tebal, flexure jelas mulai dari umbo sampai dengan tepi posterior. Keberadaan hutan mangrove mempunyai fungsi ekologisbagi berbagai jenis ikan, kerang dan biota laut lainnya. Hutan mangrove sebagai habitat alami kerang totok tersebut diduga telah mengalami penurunan akibat sedimentasi dan eksploitasi vegetasi mangrove, sedimentasi di Segara Anakan terutama berasal dari sungai Citanduy, Cibereum, dan Sungai Cikonde (Salmin, 2003). Menurut Dwiono (2003), ekosistem mangrove yang mengalami tekanan terus menerus akan berdampak pada berbagai organisme yang memanfaatkan ekosistem ini sebagai habitat, terutama kerang totok sebagai organisme bivalvia yang dominan pada ekosistem mangrove di Segara Anakan. Dengan adanya fungsi ekologis tersebut maka peranan ekosistem mangrove pada sebaran $P$. erosa menjadi sangat besar.

Penelitian yang dilakukan diharapkan dapat bermanfaat untuk mengetahui korelasi antara struktur komunitas mangrove dan kelimpahan $P$. erosa di Segara Anakan Cilacap dan memberikan informasi mengenai pengaruh faktor lingkungannya sehingga dapat digunakan dalam usaha pengelolaan dan pelestarian kerang totok dan hutan mangrove di kawasan Segara Anakan, Cilacap.

\section{BAHAN DAN METODA}

\section{Bahan}

Materi yang digunakan adalah vegetasi hutan mangrove dan kerang $P$. erosa di Segara Anakan bagian barat, Cilacap. Alat yang digunakan dalam penelitian adalah GPS (Global Positioning Sys-tem), perahu, tali rafia, meteran 1,5 m, rol meter $100 \mathrm{~m}$, golok, termometer, salt-refraktometer, lux meter, soil tester, oven, kamera, kantong plastik, timbangan analitik (ketelitian 0,001 gr), plastik sampel tanah, alumunium foil, buku identifikasi (Kitamura et al.,1997 dan Giesen et al., 2006), dan alat tulis.

\section{Lokasi dan waktu penelitian}

Hutan Mangrove Segara Anakan bagian barat, Cilacap, Jawa Tengahpada koordinat $07^{\circ} 34^{\prime} 29.42^{\prime \prime}$ LS - 07 $47^{\prime}$ 32.39" LS dan 108 $46^{\prime} 30.12^{\prime \prime}$ BT 10903'21.02" BT. Pemilihan lokasi di Segara Anakan bagian barat adalah karena daerah tersebut memiliki 
keterwakilan distribusi area mangrove, faktor kerusakan habitat karena sedimentasi, exploitasi sumberdaya yang tidak benar, konversi dan penebangan mangrove, migrasi penduduk serta faktor lain seperti belum terintegrasinya semua stakeholder dalam pengelolaan kawasan Segara Anakan serta adanya laporan dari penelitian-penelitian sebelumnya mengenai daerah tersebut (Ardli dan Widyastuti, 2001; Ardli dan Wolff, 2008; Ardli et al.,2010). Identifikasi sampel dilakukan di Laboratorium Biologi Akuatik, Fakultas Biologi Unsoed.

\section{Pengambilan sampel}

Metode yang digunakan adalah survei. Pengambilan data struktur dan komposisi vegetasi mangrove serta pengambilan sampel $P$. erosa dilakukan dengan menggunakan metode plot sampling (Mueller-Dumbois dan Ellenberg, 1974). Plot pengambilan sampel dilakukan pada area yang me-wakili distribusi area struktur komunitas mangrove dan P. erosa.

\section{Prosedur Kerja}

\section{Pemasangan plot vegetasi mangrove dan $P$. erosa}

Dibuat 11 Stasiun, pada tiap stasiun dibuat 3 plot dengan masing-masing plot seluas $10 \times 10 \mathrm{~m}$, masing-masing plot diambil data vegetasi mangrovenya (jumlah spesies, jumlah individu tiap spesies, diameter batang setinggi dada untuk pohon dan anakan pohon). Ukuran plot $10 \mathrm{~m} \times 10 \mathrm{~m}$ untuk pohon dengan diameter $\geq 10 \mathrm{~cm}$, anakan pohon(tinggi $>1,5 \mathrm{~m}$ dengan diameter $1 \mathrm{~cm}-10 \mathrm{~cm}$ ) dengan ukuran plot $5 \mathrm{~m} \times 5 \mathrm{~m}$ dan semai(ketinggian $\leq 1,5 \mathrm{~m}$ atau diameter $<1 \mathrm{~cm}$ ) dengan ukuran plot $1 \mathrm{~m} \times 1 \mathrm{~m}$. Pada masing-masing plot pengambilan sampel vegetasi mangrove dibuat kuadrat $2 \times 2 \mathrm{~m}$ secara random dan diambil sampel $P$. erosa. Setiap jenis vegetasi mangrove yang didapat diidentifikasi di Laboratorium berdasarkan
Giesen et al. (2006). Sedangkan sampel $P$. erosa diidentifikasi menggunakan buku identifikasi (Carpenter and Volker, 1998).

\section{Pengukuran parameter lingkungan}

1.Intensitas Cahaya

2. Suhu

3. $\mathrm{pH}$ tanah

4. Salinitas

5. Jenis dan tekstur tanah

6. Unsur hara

7. Kandungan air dalam tanah

8. Kandungan bahan organik

\section{Metode Analisis}

\section{Kelimpahan Mangrove dan Kerang Totok}

Data vegetasi dianalisis untuk mengetahui nilai frekuensi relatif, kerapatan relatif, dominansi relatif dan nilai penting. Rumus yang digunakan dalam penentuan struktur dan komposisi vegetasi mangrove (Mueller-Dumbois dan Ellenberg, 1974) :

Kelimpahan $P$. erosa didapat dengan menghitung jumlah $P$. erosa yang ada dari setiap kuadrat pada setiap plot lokasi penelitian.

\section{Analisis korelasi}

Analisis korelasi untuk mengetahui pengaruh faktor lingkungan abiotik yang paling berpengaruh baik terhadap struktur komunitas mangrove maupun terhadap kelimpahan $P$. erosa menggunakan analisis BIO-ENV. Menurut Clarke et al. (1993) standar pengelompokkan angka korelasi adalah:
0
: Tidak ada korelasi antara dua variabel
$>0-0,25 \quad:$ Korelasi sangat lemah
$>0,25-0,5$ : Korelasi cukup
$>0,5-0,75:$ Korelasi kuat
$>0,75-0,99$ : Korelasi sangat kuat
$1 \quad$ : Korelasi sempurna 
Tabel 1. Korelasi Antara Komposisi Vegetasi Mangrove dan Kelimpahan P. erosa di Segara Anakan, Cilacap

\begin{tabular}{|c|c|c|c|}
\hline Nilai & No Vegetasi & \multicolumn{2}{|c|}{ Keterangan } \\
\hline 0.468 & 28112124 & I Xylocarpus granatum $(P)$ & 16 Sonneratia caseolaris (AP) \\
\hline 0,463 & $2,10,11,21,24$ & 2. Nypha fruticans $(P)$ & 17. Avicennia sp. $(A P)$ \\
\hline 0,462 & $2,10,11,14,21$ & 3. Rhizophora mисronata $(P)$ & 18. Derris trifoliata $(S)$ \\
\hline 0,462 & $2,11,14,21,24$ & 4. Avicennia marina $(P)$ & 19. Acanthus ilicifolius (S) \\
\hline 0,460 & $2,11,14,15,21$ & 5. Sonneratia caseolaris $(P)$ & 20. Acanthus ebracteatus ( $S$ ) \\
\hline 0,460 & 211142125 & 6. Aegiceras corniculatum $(P)$ & 21. Avicennia marina $(S)$ \\
\hline 0,460 & 24111421 & 7. Rhizophora apiculata $(P)$ & 22. Sonneratia caseolaris $(S)$ \\
\hline 0,460 & 27111421 & 8. Xylocarpus granatum $(A P)$ & 23. Aegiceras corniculatum ( $S$ ) \\
\hline 0,460 & 2.11 .14 .21 .23 & 9. Phinu & 24. Rhizophora mucronata $(S)$ \\
\hline 0,459 & 2111421 & 11 Sonneratia alha $(A P)$ & 25. Sonneratla albu (D) \\
\hline & & 12. Avicennia marina $(A P)$ & $\boldsymbol{P}=$ Pohon \\
\hline & & 13. Rhizophora apiculata (AP) & $\boldsymbol{A P}=$ Anakan Pohon \\
\hline & & 14. Avicennia alba $(A P)$ & $\boldsymbol{S}=$ Semai, semak, herba \\
\hline & & 15. Aegiceras corniculatum (AP) & \\
\hline
\end{tabular}

\section{HASIL DAN PEMBAHASAN}

\section{Korelasi Antara Struktur Vegetasi Mangrove, Kelimpahan $P$. erosa dengan Faktor Lingkungan Abiotik}

Kuat-lemahnya hubungan antara kerapatan hutan mangrove dengan kelimpahan $P$. erosa dilakukan menggunakan analisis korelasi, besar kecilnya angka korelasi menentukan kuat atau lemahnya hubungan antara kedua variabel tersebut. Data penelitian dianalisis dengan menggunakan metode analisis Bio-ENV (Clarke et al., 1993). Analisis korelasi menggunakan analisis Bio-Env dengan sepuluh tingkat korelasi tertinggi dan lima variabel vegetasi dari masing-masing model kombinasi. Terdapat dua puluh enam vegetasi yang dikorelasikan, terdiri dari tujuh vegetasi pohon; sembilan vegetasi anakan pohon dan sembilan vegetasi semai, semak dan herba.

Bila dibandingkan dengan kelimpahan $P$. erosa di stasiun 10 sebanyak 5,66 (ind $/ \mathrm{m}^{2}$ ) dan stasiun 11 sebanyak $4\left(\mathrm{ind} / \mathrm{m}^{2}\right)$. Hal tersebut sesuai dengan pernyataan Zamroni et al. (2008) bahwa kerapatan mangrove akan mempengaruhi produksi serasah. Serasah yang jatuh akan mengalami proses dekomposisi menghasilkan detritus, sehingga makin banyak produksi serasah di vegetasi mangrove maka makin banyak pula detritus yang dihasilkan. Semakin banyak detritus yang dihasilkan akan berpengaruh terhadap kelimpahan $P$. erosa, yang sesuai dengan pernyataan Saputro (2003) bahwa detritus yang dihasilkan oleh proses dekomposisi jamur dan bakteri merupakan nutrisi yang dimanfaatkan oleh udang, ikan, kerang dan kepiting sebagai makanan termasuk oleh P. erosa. Dalam hal ini ekosistem mangrove sebagai habitat utama $P$. erosa memberikan pengaruh yang besar terhadap kelimpahan P. erosa.

Pada Tabel. 2 dapat dilihat bahwa faktor lingkungan abiotik yang paling berpengaruh terhadap vegetasi mangrove di Segara Anakan adalah salinitas dan tekstur tanah liat dengan nilai korelasi sebesar 0,362 , setiap nilai variasi korelasi menunjukan nilai yang cukup. Hasil penelitian menunjukkan rata-rata nilai salinitas di Segara Anakan adalah sebesar 10,09 ppt. Menurut Irwani et al. (2006) salinitas optimum yang dibutuhkan mangrove untuk tumbuh berkisar antara 2-22 ppt, salinitas secara langsung dapat mempengaruhi laju pertumbuhan dan zonasi mangrove, hal ini terkait dengan frekuensi penggenangan. 
Tabel 2.Korelasi Antara Struktur Vegetasi Mangrove dengan Faktor Lingkungan Abiotik

\begin{tabular}{lll}
\hline Nilai Korelasi & No Variabel & Keterangan \\
\hline 0,362 & 3,13 & 1. Suhu Udara $\left({ }^{\circ} \mathrm{C}\right)$, \\
0,347 & $3,6,13$ & 2.Suhu Tanah $\left({ }^{\circ} \mathrm{C}\right)$, \\
0,346 & $1,3,13$ & 3. Salinitas (ppt), \\
0,342 & $3,10,13$ & 4. Intensitas Cahaya Tanpa naungan (lux), \\
0,338 & $1,3,6,13$ & 5. Intensitas Cahaya dengan naungan (lux), \\
0,335 & $2,3,13$ & 6. pH tanah, \\
0,331 & $3,6,10,13$ & 7. Water Content $(\%)$, \\
0,331 & $1,3,9,13$ & 8. Bahan Organik $(\%)$, \\
0,325 & $3,9,13$ & 9. N total $(\%)$, \\
0,324 & $1,3,10,13$ & 10. P2O5 total $(\%)$, \\
& & 11. Pasir $(\%)$, \\
& 12. Debu $(\%)$, \\
& 13. Liat $(\%)$
\end{tabular}

Tabel 3. Korelasi Antara Kelimpahan P. erosa dengan faktor lingkungan abiotik

\begin{tabular}{lll}
\hline Nilai Korelasi & No Variabel & Keterangan : \\
\hline 0,412 & $6,9,10$ & 1. Suhu Udara $\left({ }^{\circ} \mathrm{C}\right)$, \\
0,394 & $1,6,9,10$ & 2.Suhu Tanah $\left({ }^{\circ} \mathrm{C}\right)$, \\
0,377 & $6,9-12$ & 3. Salinitas $(\mathrm{ppt})$, \\
0,374 & 6,9 & 4. Intensitas Cahaya Tanpa naungan (lux), \\
0,372 & $6,9-11,13$ & 5. Intensitas Cahaya dengan naungan (lux), \\
0,369 & $6,8-10$ & 6. pH tanah, \\
0,369 & $6,9,11,12$ & 7. Water Content $(\%)$, \\
0,367 & $2,6,9,10$ & 8. Bahan Organik $(\%)$, \\
0,359 & $1,6,9$ & 9. N total $(\%)$, \\
0,359 & $1,6,8-10$ & 10. P2O5 total $(\%)$, \\
& & 11. Pasir $(\%)$, \\
& 12. Debu $(\%)$, \\
& 13. Liat $(\%)$
\end{tabular}

Rata-rata suhu pada lokasi penelitian $27,81{ }^{\circ} \mathrm{C}$, menurut Salmin (2003) kisaran suhu untuk pertumbuhan mangrove yang baik adalah $>20{ }^{\circ} \mathrm{C}$, suhu optimum untuk Avicennia pada suhu $18-20{ }^{\circ} \mathrm{C}$, untuk Rhizophora $26-28$ ${ }^{\circ} \mathrm{C}$, dan untuk Xylocarpus sebesar 21-26 ${ }^{\circ} \mathrm{C}$. Hasil penelitian menunjukkan bahwa kandungan tanah liat di Segara Anakan sebesar 62,65\%, Hogart (2007) menyatakan bahwa tanah tersebut disebut liat apabila memiliki kandungan liat sebesar > 39\%. Tanah mangrove tersusun atas pasir, lanau dan liat dengan komposisi yang berbeda-beda. Kondisi tanah menyebabkan terbentuknya zonasi, misalnya tumbuhan Avicennia dan Sonneratia hidup dengan baik pada tanah berpasir, sedangkan Rhizophora lebih menyukai lumpur lembut (Zamroni, 2008).

Dari hasil analisis (lihat tabel 3) dapat dilihat korelasi antara kelimpahan $P$. erosa dengan faktor lingkungan, memiliki nilai korelasi paling tinggi yaitu sebesar 0,412 dengan faktor lingkungan yang mempengaruhinya adalah $\mathrm{pH}$ tanah, $\mathrm{N}$ total $(\%)$, dan $\mathrm{P}_{2} \mathrm{O}_{5}$ total (\%), tiga faktor lingkungan ini juga selalu muncul dalam setiap variasi korelasi. Hal tersebut menunjukkan bahwa ketiga faktor lingkungan tersebut 
berpengaruh terhadap keberadaan $P$. erosa di vegetasi mangrove. Menurut Salmin(2005) nilai $\mathrm{pH}$ tanah penting bagi kehidupan organisme di perairan payau, batas toleransi organisme terhadap $\mathrm{pH}$ bervariasi dan dipengaruhi oleh berbagai faktor, seperti temperatur, oksigen terlarut dan stadia organisme. Biota akuatik sensitif terhadap perubahan $\mathrm{pH}$ dan menyukai pH sekitar 7-8. Nilai $\mathrm{pH}$ pada lokasi penelitian memiliki kisaran 5,8 - 7, hal ini sesuai dengan pernyataan Dwiono (2003), bivalvia dapat hidup dan berkembang biak dengan baik dengan derajat keasaman suatu perairan yang sesuai berkisar antara 5,6-8,3. Hasil penelitian menunjukkan jumlah $\mathrm{N}$ total adalah sebesar $0,43 \%$ dan nilai $\mathrm{P}_{2} \mathrm{O}_{5}$ total sebesar $0,16 \%$.

Dua nutrien yang paling penting di daerah perairan adalah nitrogen dan fosfor, karena kedua nutrien tersebut keberadaannya terbatas dan dibutuhkan untuk pertumbuhan fitoplankton dan diatom. Di dalam air, urea secara cepat terhidrolisis menjadi amonium yang dapat langsung dimanfaatkan oleh fitoplankton. Amonium dapat juga teroksidasi menjadi nitrat oleh bakteri nitrifikasi yang dapat dimanfaatkan langsung oleh fitoplankton.

Nitrogen pada material organik tanah akan dimineralisasi menjadi amonia dan kembali ke dalam air sehingga dapat dimanfaatkan kembali oleh fitoplankton (Salmin, 2005). Fosfor dimanfaatkan oleh fitoplankton dalam bentuk ortofosfat (PO43-) dan terakumulasi dalam tubuh ikan/udang melalui rantai makanan. Phosphat yang tidak diserap oleh fitoplankton akan diikat oleh tanah. Kemampuan mengikat tanah dipengaruhi oleh kandungan liat (clay) tanah. Semakin tinggi kandungan liat pada tanah, semakin meningkat kemampuan tanah mengikat fosfat. Hal tersebut berkaitan dengan pernyataan Dwiono (2003), bahwa lebih dari $40 \%$ makanan $P$. erosa adalah plankton yaitu dari Bacillariophicheae dan dari beberapa filum protozoa serta $30 \%$ berupa detritus.

\section{Komposisi Vegetasi Mangrove di Segara Anakan, Cilacap}

Spesies mangrove dikelompokkan menjadi 3 kelompok yaitu pohon dengan diameter $\geq 10 \mathrm{~cm}$, anakan pohondiameter $1-10 \mathrm{~cm}$ dan semai dengan diameter $<1 \mathrm{~cm}$ (Kitamura et al.,1997; Noor et al.,2006; Giesen et al.,2006). Struktur dan komposisi vegetasi mangrove pada tingkat pohon di Segara Anakan, Cilacap dapat dilihat dari hasil perhitungan nilai Frekuensi Relatif (FR), Kerapatan Relatif (KR), Dominansi Relatif (DR), dan Nilai Penting (NP) masing-masing vegetasi di Segara Anakan.

Hasil penelitian menunjukkan bahwa komposisi vegetasi mangrove di Segara Anakan pada tingkat pohon didominasi oleh Avicennia marina dengan nilai penting sebesar $136,60 \%$. Kemudian diikuti oleh Sonneratia caseolaris ( $\mathrm{NP}=43,91 \%$ ) dan Aegiceras corniculatum ( $\mathrm{NP}=43,90 \%)$. Atikasari (2011) menjelaskan, struktur komunitas vegetasi mangrove di Segara Anakan pada tingkat pohon memiliki nilai penting masing - masing adalah Avicennia alba $(\mathrm{NP}=127,01 \%)$, Sonneratia caseolaris $(\mathrm{NP}=62,59 \%)$ dan Avicennia sp. $(\mathrm{NP}=30,09 \%)$. Dari data tersebut dapat terlihat adanya perbedaan kerapatan spesies dan spesies vegetasi mangrove mengalami penurunan nilai penting, hal tersebut dapat diakibatkan oleh faktor kerusakan habitat karena sedimentasi, exploitasi sumberdaya yang tidak benar, dan penebangan mangrove (Ardli dan Wolff, 2008).

A. marina merupakan vegetasi mangrove paling dominan yang ada di Segara Anakan. Menurut Kitamura et al. (1997), A. marina merupakan jenis mangrove sejati yang tumbuh pada lahan pantai yang terlindung, memiliki kemampuan menempati dan tumbuh pada berbagai habitat pasang-surut, bahkan di tempat asin sekalipun. Spesies ini merupakan salah satu jenis tumbuhan yang paling umum ditemukan di habitat pasang-surut. A. marina biasanya memiliki ketinggian sampai $12 \mathrm{~m}$, 
bahkan ada yang hingga $30 \mathrm{~m}$. Spesies ini dapat berupa pohon yang tumbuh tegak dan memiliki sistem perakaran horizontal yang rumit dan berbentuk pensil, akar nafas dengan sejumlah lentisel. Daun Avicennia marina berbentuk elips dan bulat memanjang, pada bagian atas permukaan daun ditutupi bintik-bintik kelenjar berbentuk cekung dengan warna di bagian bawah daun putih abu-abu.

Giesen et al. (2006) menerangkan bahwa Sonneratia caseolaris merupakan vegetasi mangrove dari Familia Sonneratiaceae yang memiliki ciri-ciri antara lain ; Pohon selalu hijau, tumbuh tersebar, dan dapat mencapai ketinggian hingga $15 \mathrm{~m}$. Kulit kayu berwarna putih tua hingga coklat, dengan celah longitudinal yang halus. Akar berbentuk kabel di bawah tanah dan muncul ke permukaan sebagai akar nafas yang berbentuk kerucut tumpul dan tingginya mencapai $25 \mathrm{~cm}$ (Noor et al., 2006).

Aegiceras corniculatum merupakan pohon yang tumbuh lurus dengan ketinggian pohon mencapai $6 \mathrm{~m}$, akar menjalar di permukaan tanah. Kulit kayu bagian luar abu-abu hingga coklat kemerahan, bercelah, serta memiliki sejumlah lentisel. Memiliki daun berkulit, terang, berwarna hijau mengkilat pada bagian atas dan hijau pucat di bagian bawah, seringkali bercampur warna agak kemerahan. Menurut Noor et al. (2006) mangrove ini memiliki toleransi yang tinggi terhadap salinitas, tanah dan cahaya yang beragam.

Berdasarkan hasil penelitian dapat dilihat bahwa vegetasi yang paling mendominasi pada tingkat anakan pohon adalah Avicennia marina $(\mathrm{NP}=$ $102,88 \%)$, Rhizophora apiculata (NP= 59,80\%) dan Aegiceras corniculatum $(\mathrm{NP}=56,32 \%)$, hal tersebut menunjukkan bahwa vegetasi tersebut memiliki kerapatan dan dominansi paling tinggi di Segara Anakan, Cilacap. Sedangkan Avicennia sp. dan Xylocarpus granatum yaitu masing-masing mempunyai nilai penting $5,18 \%$ dan $10,25 \%$, menurut Kathiseran et al. (2001) spesies mangrove mempunyai perbedaan dalam seberapa lama propagul dapat bertahan hidup, dapat disebabkan oleh pembentukan propagulyang baik, tingkat pertumbuhannya yang tinggi dan batas toleransinya terhadap faktor lingkungan.

Habitat tempat penelitian lebih mendukung untuk $A$. marina yaitu berupa tanah berpasir yang menurut Zamroni (2008), Avicennia dapat hidup dengan baik pada tanah berpasir. Avicennia marina juga merupakan vegetasi mangrove yang tumbuh pertama kali di area tanah timbul (Ardli dan Widyastuti, 2010), hal tersebut sesuai dengan pernyataan Ardli dan Wolff (2008) bahwa seluas $1.741,1$ ha mangrove baru terbentuk di area tanah timbul di kawasan Segara Anakan.

Berdasarkan hasil penelitian dapat dilihat vegetasi semak di dominasi oleh Derris trifoliata $(\mathrm{NP}=74,93 \%)$, diikuti oleh Acanthus ebracteatus $(\mathrm{NP}=$ 55,67\%) dan Acanthus ilicifolius memiliki kerapatan paling rendah ditingkat semak sebesar $(\mathrm{NP}=54,17 \%)$. Pada jenis herba terdapat Acrosticum aurilum dengan $(\mathrm{NP}=1,31 \%)$. Sedangkan pada tingkat semai didominasi oleh Aegiceras corniculatum $(\mathrm{NP}=5,26 \%)$, diikuti oleh Avicennia marina $(\mathrm{NP}=3,28 \%)$, Rhizophora mucronata (NP $=2,81 \%$ ), dan Sonneratia alba $(\mathrm{NP}=2,53 \%)$.

Menurut Noor et al. (2006) Derris trifoliata berasal dari familia Fabaceae, Derris memiliki ciri-ciri antara lain merupakan tumbuhan pemanjat/perambat berkayu, dengan panjang mencapi 15 $\mathrm{m}$ atau lebih. Vegetasi mangrove ikutan ini dapat ditemukan pada substrat berpasir dan berlumpur di bagian tepi daratan dari habitat mangrove. Acanthus merupakan vegetasi dari familia Acanthaceae, pada lokasi penelitian banyak dijumpai spesies Acanthus ilicifolius dan Acanthus ebracteatus, jenis ini memiliki ciri-ciri antara lain merupakan jenis tumbuhan semak, terjurai di permukaan tanah, kuat, agak berkayu, ketinggian hingga $2 \mathrm{~m}$. Kitamura et al. (1997) menambahkan Acanthus dapat tumbuh kokoh dan banyak terdapat di area mangrove. 


\section{Kelimpahan $P$. erosa di Segara Anakan, Cilacap}

Berdasarkan hasil penelitian dapat dilihat nilai rata-rata kelimpahan individu $P$. erosa terbanyak terdapat di stasiun 3 yaitu sebanyak $10,77 \mathrm{ind} / \mathrm{m}^{2}$. Diikuti oleh stasiun 4 sebanyak 6,6 $\mathrm{ind} / \mathrm{m}^{2}$ dan stasiun 5 sebanyak 5,89 ind $/ \mathrm{m}^{2}$. Tetapi untuk stasiun 1,2 dan 8 tidak ditemukan spesies $P$. erosa. Hal tersebut diduga dikarenakan adanya pengaruh kerapatan vegetasi mangrove di masing-masing stasiun, stasiun 1,2 dan 8 memiliki kerapatan paling rendah dibandingkan stasiun lainnya, kepadatan $P$. erosa tersebut berkaitan erat dengan kondisi lingkungan dan faktor makanan yang sesuai dengan pernyataan Nurdin et al. (2008) bahwa ketersediaan makanan akan mempengaruhi organisme, kerapatan mangrove akan mempengaruhi produksi serasah. Makin banyak serasah yang dihasilkan, maka semakin banyak pula detritus yang dihasilkan.

\section{KESIMPULAN DAN SARAN}

\section{Kesimpulan}

1. Salinitas dan tekstur tanah liat merupakan faktor lingkungan abiotik yang paling berpengaruh terhadap struktur komunitas mangrove di Segara Anakan Cilacap.

2. Nilai $\mathrm{pH}, \mathrm{N}$ total $(\%)$, dan $\mathrm{P}_{2} \mathrm{O}_{5}$ total (\%) merupakan faktor lingkungan yang paling berpengaruh terhadap kelimpahan $P$. erosa di ekosistem mangrove Segara Anakan.

3. Korelasi vegetasi mangrove dengan kelimpahan Polymesoda erosa termasuk kedalam korelasi cukup dengan nilai korelasi sebesar 0,459 0,46

\section{Saran}

Perlu dikaji lebih lanjut mengenai faktor lain misalnya aktivitas manusia terhadap kondisi vegetasi mangrove khususnya vegetasi pionir. Ditemukan- nya banyak penebangan liar di Segara Anakan, perlu dilakukan pengawasan menyeluruh dan lebih ketat terkait keamanan dan kelestarian hutan mangrove Segara Anakan Cilacap oleh seluruh pemegang kepentingan.

\section{DAFTAR REFERENSI}

Ardli, E.R. and A. Widyastuti. 2001. Application of NDVI analysis from Landsat TM and SPOT images for monitoring and detection of mangrove damages at Segara Anakan Cilacap, Central Java. (in Bahasa Indonesia). DUE-like project Unsoed, Purwokerto.

Ardli, E.R. and M. Wolff. 2008. Quantifying Habitat and Resource Use Changes in the Segara Anakan Lagoon (Cilacap. Indonesia) Over the Past 25 Year (1978 - 2004). Asian Journal oJ Water, Environment and Pollution, 5 (4): 59-67.

Ardli E.R., E. Yani dan A. Widyastuti. 2010. Distribusi Spasial dan Dinamika Populasi Polymesoda erosa di Ekosistem Mangrove Segara Anakan Cilacap, Sebagai Acuan Restocking dan Konservasi. Laporan Penelitian. Fakultas Biologi Universitas Jenderal Soedirman, Purwokerto.

Atikasari, Y. 2011. Distribusi Vegetasi Mangrove Pionir Segara Anakan Cilacap. Skripsi. Fakultas Biologi Universitas Jenderal Soedirman, Purwokerto.

Carpenter, K.E and Volker H.N. 1998. The Living Marine Resources of The western Central Pacific. FAO Organization of The United Nations. Roma, Italy.

Clarke, K.r., M. Ainsworth. 1993. A method of linking multivariate community structure to 
environmental variables. Marine Ecology Progress Series. 92 : 205-219.

Dwiono, S.A.P. 2003. Pengenalan Kerang Mangrove, Geloina erosa dan Geloina expansa. Balitbang Sumberdaya Laut, Pusat Penelitian Oseanografi-LIPI, Jakarta. Oceana, 28 (2) : 31-38.

Giesen, W., S. Wullffraat, M. Zieren., L. Scholten. 2006. Mangrove Guide Book For Southeast Asia. FAO and Wetlands International. Thailand.

Hogart, P. 2007. The Biology of Mangroves and Seagrasses. Oxford University Press Inc., New York.

Irwani,A. dan C.A. Suryono. 2006. Struktur Populasi dan Distribusi Kerang Totok Geloina sp. (Bivalvia : Corbiculidae) di Segara Anakan Cilacap Ditinjau dari Aspek Degradasi Salinitas. Ilmu Kelautan, 11(1):54-58.
Kitamura, S., C. Anwar, A. Chaniago and S. Baba. 1997. Handbook of mangrove in Indonesia: Bali and Lombok. International Society for Mangrove Ecosystem. Denpasar. $119 \mathrm{hlm}$.

Mueller-Dombois, D. and H. Ellenberg. 1974. Aims and Methods of Vegetation Ecology. John Wiley, London.

Noor, Y.R., M. Khazali dan N.N. Suryadiputra. 2006. Panduan Pengenalan Mangrove di Indonesia. Wetlands International Indonesia Programe. Bogor.

Salmin. 2005. Oksigen Terlarut (DO) dan Kebutuhan oksigen Biologi (BOD) sebagai Salah satu Indikator Menentukan Kualitas air. Oseana, XXX (3) : 21-26.

Zamroni, Y dan Rohyani, I. S. 2008. Produksi Serasah Hutan Mangrove di Perairan Pantai Teluk Sepi. Lombok Barat. Biodiversitas. 9(4) : 284-287. 